\title{
Research on Countermeasures and Financing Risk of Small and Medium-Sized Enterprises in China
}

\author{
Chuanyang Gong ${ }^{1,2}$ \\ ${ }^{1}$ School of Management Shanghai University, China \\ ${ }^{2}$ College of Economics and Management ZheJiang A\&F University, China \\ Correspondence: Chuanyang Gong, School of Management Shanghai University, China. E-mail: \\ gcy17610@163.com
}

Received: March 9, 2021

Accepted: May 5, 2021

Online Published: May 28, 2021

doi:10.5539/ijbm.v16n6p79

URL: https://doi.org/10.5539/ijbm.v16n6p79

\begin{abstract}
SMEs have played an important role in deepening of construction of socialist market economy in China. Their contribution rate to our country's economy is rising continuously, they also stimulate technical innovation. However, because of their small scale, credit margin and other factors and imperfect market mechanism, SMEs are facing a severe situation in the process of financing, the huge financing risk has become the core problem restricting the development of SMEs. This paper employed the KMV model to make an empirical analysis. Then, the author puts forward corresponding suggestions for the financing of SMEs in the future.
\end{abstract}

Keyword: small and medium-sized enterprises, financing risk, KMV model

\section{Introduction}

According to the in-depth market research and investment strategy research and analysis report of China's enterprise business project industry from 2017 to 2022, there are 40 million small and medium-sized enterprises in China, accounting for $99 \%$ of the total number of enterprises, contributing $60 \%$ of China's GDP, $50 \%$ of taxes and $80 \%$ of urban employment. Small and medium-sized enterprises play an important role in promoting economic prosperity, promoting reform and innovation, increasing export employment, etc., and play an important role in economic and social development. However, SMEs have to face the difficult problem of financing. There are many reasons for the financing difficulties of small and medium-sized enterprises, among which the financing risk is the key factor restricting the financing of small and medium-sized enterprises. Due to the small assets, low credit, high failure rate and default rate of small and medium-sized enterprises, banks are often reluctant to provide loans to them, and some other financing channels are difficult to meet the huge capital needs of enterprises, or need to pay huge interest. Therefore, it is of practical significance to study the financing risk of small and medium-sized enterprises. This paper lists the main financing risks faced by small and medium-sized enterprises, and with the help of KMV model, taking listed enterprises in Zhejiang Province as samples, analyzes the default risks of small and medium-sized enterprises, and puts forward corresponding suggestions, hoping to help find countermeasures to reduce the financing risks of small and medium-sized enterprises.

\section{Literature}

Scholars at home and abroad have made profound explorations on the financing risks of small and medium-sized enterprises: Li Suhong, Chen Liwen and Wang Shuqiang (2013) found that the policy and legal risks faced by enterprises are the largest, followed by financial risks; Fang Xianming and Su Xiaojun (2015) divided the main financing risks of Science and technology enterprises into market risks, environmental risks and production risks On this basis, it subdivides various levels and establishes a clear financing risk evaluation system. When studying the financing risk of Listed Companies in strategic emerging industries, Tian JuanJuan (2016) empirically concludes that the extreme risk loss of gem is the largest, and it is more vulnerable to environmental factors, and gem is usually the main way for small and medium-sized enterprises to list. Wang Cheng Li and Xu Jiuping (2003) found that the risk of private enterprises listed on the gem is relatively high after their risk evaluation. Yang Kaiyu (2015) measured the credit risk of companies listed on the gem, and found that the overall credit level of companies listed on the gem is lower than that of small and medium-sized enterprises, that 
is to say, their default risk is much higher than that of companies listed on the SME board.

Zhang Peng and Cao Yang (2012) use KMV model to calculate the default distance and default probability of sample listed companies. The empirical results show that the default distance can better identify the credit risk of listed companies. Chen Xiaohong, Zhang Zejing et al. (2009) used KMV model to conduct a more specific study on the credit risk of China's small and medium-sized listed companies in 2006, and found that compared with large enterprises, the default risk of small and medium-sized companies had an increasing trend in 2006, and set two credit warning lines to monitor the credit crisis of small and medium-sized listed companies; Peng Wei (2012) selected 1 Taking 11 ST companies and non ST companies as the research objects, this paper uses the improved KMV model to calculate their average default distance from 2008 to 2011, and considers that the KMV model can well measure and distinguish the credit risk of Listed SMEs. The research results of many scholars show that the traditional KMV model can reflect the level of default risk, and has high sensitivity to default risk. To sum up, this paper selects KMV model to evaluate the default risk of Listed SMEs.

\section{Model Construction and Data Sources}

\subsection{Model construction}

(1) Calculate the market value and volatility of assets

According to the above analysis, KMV model can be derived from BSM option pricing formula:

$$
V_{E}=V_{A} N\left(d_{1}\right)-D e^{-r f \tau} N\left(d_{2}\right)
$$

By deriving the two sides of the formula and then calculating the expectation, we can get the following results:

$$
\sigma_{E}=\frac{V_{A} N\left(d_{1}\right)}{V_{E}} \sigma_{A}
$$

Among, $d_{1}=\frac{\ln \left(V_{A} / D\right)+\left(r_{f}+0.5 \sigma^{2}{ }_{A}\right) \tau}{\sigma_{A} \sqrt{\tau}}, \quad d_{2}=d_{1}-\sigma_{A} \sqrt{\tau}$

Where is the equity value of the company, is the market value of the company's assets, is the standard normal cumulative distribution function, D is the book value of the company's liabilities, is the risk-free interest rate, is the debt maturity, is the volatility of the company's equity value, is the volatility of the company's assets market value. The equity value and its volatility of the company's assets can be observed and calculated in the stock market. Therefore, the market value and volatility of the company's assets can be calculated by combining the above four equations.

(2) Calculate the default point DP and default distance DD of the company

Theoretically, the point where the asset value and liability value of listed companies are equal is

the point of default. However, a large number of scholars have found that most enterprises tend to use long-term liabilities to repay short-term liabilities. KMV company has calculated through a large number of empirical tests that the empirical point of default is generally half of the book value of short-term debt and long-term debt, that is, the default point is the default point of short-term debt plus long-term debt among them, SD is short-term debt and LD is long-term debt.

The default distance DD refers to the multiple of the product of the distance between the market

value of the company's assets and the default point, the market value of the company's assets and its volatility:

$$
D D=\frac{V_{A}-D P}{V_{A} \times \sigma_{A}}
$$

\section{(3) Calculate EDF}

Assuming that the asset value of a company obeys normal distribution, the default distance reflects the standard deviation of the company from default:

$$
\mathrm{EDF}=\mathrm{N}(-\mathrm{DD})
$$




\subsection{Data Sources}

This paper selects Zhejiang small and medium-sized enterprises listed on the SME and gem as samples. The basis of selection is that the operating income in 2017 is less than 400million yuan, excluding ST, ST listed enterprises, financial, insurance listed enterprises and enterprises with incomplete or abnormal data, and finally leaving 25 SMEs. The research period is from January 1, 2017 to December 31, 2017. The original data is from the national Tai'an database. According to the calculation method and steps of KMV model above, the data of 25 selected enterprises are calculated by Excel, and the equity value, volatility and default point of the selected enterprises are calculated; Matlab 2016a is used The statistical software program the parameters in KMV model, and through iterations to find the market value and volatility of enterprise assets, and finally obtain the default distance and expected default probability of 25 enterprises in 2017.

\section{Empirical Results and Analysis}

\subsection{Calculate the Volatility of Equity Value}

the First, the daily return of the stock is calculated according to the formula ${ }_{u_{i}=\ln \left(\frac{P_{i}}{P_{i-1}}\right)}$, and then the daily volatility of stock return $\sigma_{o}=\sqrt{\frac{1}{n-1} \sum_{i=1}\left(u_{i}-\overline{u_{i}}\right)^{2}}$ is calculated. Finally, the annual volatility of the stock price $\sigma_{E}=\sigma_{o} \times \sqrt{244}$ is calculated according to the trading day of the stock market in 2017. According to the formula:

$V_{E}=$ number of circulating shares $\times$ closing price at the end of the year + number of non tradable shares $\times$ net assets per share at the end of the year

The equity value of each enterprise is obtained. The calculation results are as follows:

Table 1 . Stock price volatility and equity value of enterprises

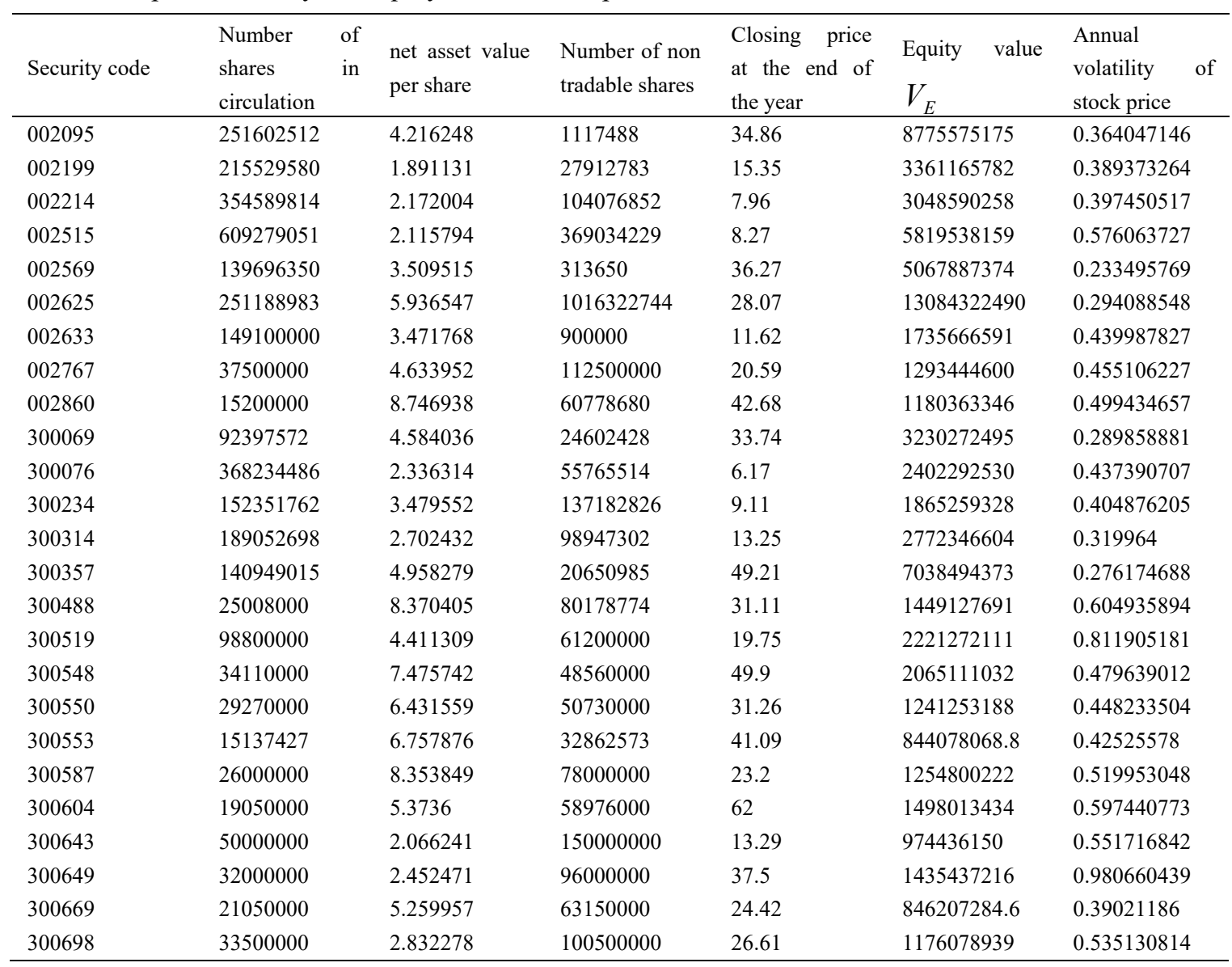




\subsection{Calculation of Default Point and Total Liabilities}

Connecting with practice, short-term debt is selected as current liability in financial report, and long-term debt is replaced by non current liability. Then the formula is adjusted as follows:

Default point $\mathrm{DP}=$ current liability $+0.5 *$ non current liability, total liability $\mathrm{d}=$ current liability + non current liability

The calculation results are as follows:

Table 2. Total liabilities and default points of enterprises

\begin{tabular}{lllll}
\hline Security code & current liabilities & Non current liabilities & Total liabilities D & Default point DP \\
\hline 002095 & 226614027.9 & 2587016.69 & 229201044.6 & 227907536.3 \\
002199 & 121901907.4 & 927716.69 & 122829624.1 & 122365765.8 \\
002214 & 347299175.4 & 83934441.65 & 431233617 & 389266396.2 \\
002515 & 208855012.2 & 26421441.03 & 235276453.2 & 222065732.7 \\
002569 & 221104337.6 & 0 & 221104337.6 & 221104337.6 \\
002625 & 525865142.7 & 244214163.7 & 770079306.4 & 647972224.5 \\
002633 & 72049355.52 & 20290554.19 & 92339909.71 & 82194632.62 \\
002767 & 117747404.2 & 2728619.59 & 120476023.8 & 119111714 \\
002860 & 147067906.5 & 737681.57 & 147805588.1 & 147436747.3 \\
300069 & 361556249.9 & 5347815.31 & 366904065.2 & 364230157.6 \\
300076 & 119412595.6 & 12142611.29 & 131555206.9 & 125483901.3 \\
300234 & 200140975.5 & 11677053.25 & 211818028.8 & 205979502.1 \\
300314 & 85672383.26 & 3349016.79 & 89021400.05 & 87346891.66 \\
300357 & 42200071.04 & 4853200 & 47053271.04 & 44626671.04 \\
300488 & 129191271.4 & 40663251.06 & 169854522.5 & 149522896.9 \\
300519 & 57908489.39 & 11329603.66 & 69238093.05 & 63573291.22 \\
300548 & 63511946.36 & 5663775.32 & 69175721.68 & 66343834.02 \\
300550 & 177298816.1 & 1097104.79 & 178395920.9 & 177847368.5 \\
300553 & 30942155.05 & 0 & 30942155.05 & 30942155.05 \\
300587 & 113905531.3 & 6594544.52 & 120500075.8 & 117202803.5 \\
300604 & 117110161.6 & 3114355.78 & 120224517.4 & 118667339.5 \\
300643 & 63238935.54 & 2528538.44 & 65767473.98 & 64503204.76 \\
300649 & 48565537.34 & 1945905.49 & 50511442.83 & 49538490.09 \\
300669 & 43406896.63 & 0 & 43406896.63 & 43406896.63 \\
300698 & 189048322 & 0 & 189048322 & 189048322 \\
\hline
\end{tabular}

4.3 Calculate Asset Volatility, Asset Value, Default Distance and Default Probability

Simultaneous formula:

$$
\begin{gathered}
V_{E}=V_{A} N\left(d_{1}\right)-D e^{-r f \tau} N\left(d_{2}\right) \\
\sigma_{E}=\frac{V_{A} N\left(d_{1}\right)}{V_{E}} \sigma_{A} \\
d_{1}=\frac{\ln \left(V_{A} / D\right)+\left(r_{f}+0.5 \sigma^{2}{ }_{A}\right) \tau}{\sigma_{A} \sqrt{\tau}} \\
d_{2}=d_{1}-\sigma_{A} \sqrt{\tau}
\end{gathered}
$$

The asset value and the volatility of asset value are obtained, among: $\tau=1, \mathrm{r}=1.5 \%$. Again according to $D D=\frac{V_{A}-D P}{V_{A} \times \sigma_{A}}, \quad \mathrm{EDF}=\mathrm{N}(-\mathrm{DD})$, The default distance and default probability are obtained. This step is solved by MATLAB 2016a statistical software. The calculation results are as follows: 
Table 3. Asset value, asset volatility, default distance and default probability of enterprises

\begin{tabular}{lllll}
\hline Security code & asset value & Asset value volatility & Default distance & Probability of default \\
\hline 002095 & $9.00 \mathrm{E}+09$ & 0.35491476 & 2.74623906 & 0.003014141 \\
002199 & $3.48 \mathrm{E}+09$ & 0.375843031 & 2.567186892 & 0.005126367 \\
002214 & $3.47 \mathrm{E}+09$ & 0.348840474 & 2.545373817 & 0.00545804 \\
002515 & $6.05 \mathrm{E}+09$ & 0.553999687 & 1.738814841 & 0.041033669 \\
002569 & $5.29 \mathrm{E}+09$ & 0.223873902 & 4.279951027 & $9.35 \mathrm{E}-06$ \\
002625 & $1.38 \mathrm{E}+10$ & 0.277972041 & 3.42908994 & $3.03 \mathrm{E}-04$ \\
002633 & $1.83 \mathrm{E}+09$ & 0.418076701 & 2.284274811 & 0.011177693 \\
002767 & $1.41 \mathrm{E}+09$ & 0.416856773 & 2.196559839 & 0.014025949 \\
002860 & $1.33 \mathrm{E}+09$ & 0.444591615 & 1.999156572 & 0.022795708 \\
300069 & $3.59 \mathrm{E}+09$ & 0.260689786 & 3.446976443 & $2.83 \mathrm{E}-04$ \\
300076 & $2.53 \mathrm{E}+09$ & 0.415002542 & 2.290199529 & 0.011004876 \\
300234 & $2.07 \mathrm{E}+09$ & 0.364140244 & 2.473446076 & 0.00669085 \\
300314 & $2.86 \mathrm{E}+09$ & 0.310153105 & 3.125745212 & $8.87 \mathrm{E}-04$ \\
300357 & $7.08 \mathrm{E}+09$ & 0.27436781 & 3.621784606 & $1.46 \mathrm{E}-04$ \\
300488 & $1.62 \mathrm{E}+09$ & 0.54231908 & 1.673367935 & 0.047127443 \\
300519 & $2.29 \mathrm{E}+09$ & 0.787717627 & 1.234239768 & 0.108556786 \\
300548 & $2.13 \mathrm{E}+09$ & 0.464317182 & 2.086720565 & 0.018456701 \\
300550 & $1.42 \mathrm{E}+09$ & 0.392642181 & 2.227192207 & 0.012967215 \\
300553 & $8.75 \mathrm{E}+08$ & 0.410434116 & 2.350242563 & 0.00938059 \\
300587 & $1.37 \mathrm{E}+09$ & 0.475015828 & 1.925554572 & 0.027080008 \\
300604 & $1.62 \mathrm{E}+09$ & 0.553667406 & 1.673545493 & 0.047109979 \\
300643 & $1.04 \mathrm{E}+09$ & 0.517321189 & 1.813054293 & 0.034911724 \\
300649 & $1.49 \mathrm{E}+09$ & 0.94783457 & 1.019845631 & 0.153900839 \\
300669 & $8.89 \mathrm{E}+08$ & 0.371442101 & 2.560753291 & 0.005222275 \\
300698 & $1.36 \mathrm{E}+09$ & 0.461977668 & 1.864223924 & 0.031145133 \\
\hline
\end{tabular}

From the above data, it can be seen that among the 25 listed SMEs in Zhejiang Province, the default probability of 5 enterprises is less than $0.3 \%$, and that of 14 enterprises is $1 \%$, the largest of which is $15.39 \%$ (securities code 300649), indicating that SMEs are still facing a high default risk. The reference interval of default probability given by the internationally famous Moody's company using KMV model is [0.02\%, 20\%] (Han, 2018). Therefore, the expected default rate calculated in this paper has a high degree of credibility, which also proves that KMV model has a certain applicability in China's market, and can more accurately measure the default risk of listed enterprises.

\subsection{Regression Analysis of the Model}

The default distance is set as the dependent variable, with equity value, equity value volatility, default point, asset value and asset value volatility as the independent variables respectively. The regression analysis is carried out by SPSS software, and it is found that the annual volatility of equity value and default distance have the highest fitting degree, the results are as follows:

\begin{tabular}{|c|c|c|c|c|c|c|}
\hline \multicolumn{7}{|c|}{ Model summary } \\
\hline Model & \multicolumn{2}{|c|}{$\mathrm{R}$} & R square & \multicolumn{2}{|l|}{ adjustment } & $\begin{array}{l}\text { Error in standard } \\
\text { estimation }\end{array}$ \\
\hline \multicolumn{2}{|l|}{1} & $.899^{\mathrm{a}}$ & 0.808 & \multicolumn{2}{|l|}{0.8} & 0.339997913 \\
\hline \multicolumn{7}{|c|}{ a forecast variables: (constant), annual volatility of stock price } \\
\hline \multicolumn{7}{|c|}{ ANOVA $^{\mathrm{a}}$} \\
\hline \multirow[t]{2}{*}{ Model } & & Sum of squares & freedom & mean square & $\mathrm{F}$ & Significance \\
\hline & regression & 11.194 & 1 & 11.194 & 96.838 & $.000^{\mathrm{b}}$ \\
\hline \multirow[t]{2}{*}{1} & residual & 2.659 & 23 & 0.116 & & \\
\hline & Sum & 13.853 & 24 & & & \\
\hline
\end{tabular}




\begin{tabular}{|c|c|c|c|c|c|c|}
\hline \multicolumn{7}{|c|}{ Coefficient $^{\mathrm{a}}$} \\
\hline \multirow[t]{2}{*}{ Model } & & \multicolumn{2}{|c|}{ Non standardized coefficient } & \multirow{2}{*}{$\begin{array}{l}\text { standardized } \\
\text { coefficient }\end{array}$} & \multirow[t]{2}{*}{$\mathrm{t}$} & \multirow[t]{2}{*}{ Significance } \\
\hline & & B & Standard error & & & \\
\hline \multirow[b]{2}{*}{1} & (constant) & 4.305 & 0.208 & & 20.663 & 0 \\
\hline & $\begin{array}{l}\text { Annual volatility } \\
\text { of equity }\end{array}$ & -4.133 & 0.42 & -0.899 & -9.841 & 0 \\
\hline \multicolumn{7}{|c|}{ a Dependent variable: default distance } \\
\hline
\end{tabular}

According to the results, the fitting degree is 0.899 , close to 1 , indicating that the model has a high degree of fitting; the significance of $F$ value is 0 , indicating that the volatility of equity value has a significant impact on the default distance; the significance of $t$ test is 0 , indicating that the volatility of equity value has a significant impact on the default distance.

\section{Research Conclusions and Recommendations}

Based on KMV model, this paper makes an empirical analysis of small and medium-sized listed enterprises in Zhejiang Province. The conclusions are as follows: small and medium-sized enterprises in China are faced with high default risk, and their default probability is mainly positively correlated with the volatility of equity value, that is, the greater the annual volatility of stock price is, the greater the default probability is. The following countermeasures and suggestions are put forward:

(1) Strengthen credit management and improve business reputation. While implementing credit management for the company's internal business and employees, we should also pay attention to risk prevention, establish customer credit files, strengthen customer credit management, update and modify the information in time, and optimize the enterprise credit management mechanism (Wang \& Li, 2007). (2) Broaden financing channels and disperse financing risks. (3) To improve the financing risk prevention mechanism, enterprises can establish a special risk management department and form a complete risk prevention system according to their own development and internal resources. (4) We should strengthen the prediction of interest rate and reasonably determine the financing mode, financing period and financing time. Small and medium-sized enterprises should strive for policy financing as far as possible. Policy financing is the product of the combination of financial means and government policies. It is a financing business and behavior based on policy basis and guidance ${ }^{[13]}$. (5) Moderate debt management, enhance the strength of enterprises. Debt operation is a double-edged sword. From a positive analysis, it can quickly raise funds, strengthen operation and management, reduce tax burden, and avoid dispersing the controlling power of enterprises (Han, 2018).

\section{References}

Baofu, W., \& Nan, L. (2007). Empirical Study on default probability of Listed Companies. Business Era, (18), 78-79.

Chengli, W., Jiuping, X. (2003). Comparative study on financing risk of private enterprises listed on GEM. Contemporary Finance and Economics, (3), 60-63.

Hui, H. (2018). Analysis on the financing difficulties of small and medium-sized enterprises in Henan Province from the perspective of small and medium-sized enterprises themselves. Journal of the Party School of Zhengzhou Municipal Party Committee, (4), 74-77.

Jianhui, M. (2003). Small and medium sized enterprises listed on gem: risks and countermeasures. Beijing Society of business economics. Special issue of 2003 annual meeting of small and medium sized circulation enterprises in Beijing. Beijing Society of Business Economics: Beijing Society of business economics.

Juanjuan, T. (2016). Research on financing efficiency and risk of strategic emerging industries. Northeast University of Finance and economics.

Jun, C., Feixia, W., \& Wei, W. (2009). Analysis of the causes of legal risks in enterprises and preventive measures. Economist, (3), 96-104.

Junyong, L. (2014). Financial risks of small and medium-sized enterprises and preventive measures. Chinese and Foreign Entrepreneurs, (31), 90-93.

Kaiyu, Y. (2015). Application analysis of modified KMV model in credit risk measurement of GEM listed companies. Western Finance, (5), 46-56. 
Lixia. D. (2017). Mechanism research on policy financing supporting micro finance development in Gansu Province from the perspective of anti-poverty. Productivity Research, (3), 22-68.

Peng, Z., \& Yang, C. (2012). Research on credit risk measurement of Listed Companies. Research on Financial Issues, (3), 66-71.

Suhong, L., Liwen, C., \& Shuqiang, W. (2013). Financing risk evaluation based on Fuzzy Analytic Hierarchy Process -taking real estate development enterprises in Hebei Province as an example. Enterprise economy, 32(2), 137-140.

Wei, P. (2012). Research on credit risk of Listed SMEs based on KMV model. Southern Finance, (3), 23-30.

Xianming, F., \&Xiaojun, S. (2015). Financing risk of science and technology enterprises: source, evaluation and control [J]. Research on science and technology management, 2015,35 (21): 62-67.

Xinmin, D., Qing, S. (2008). On the risk and prevention of MBO from the perspective of internal control. Financial and accounting Bulletin (Academic Edition), (10), 102-104.

\section{Copyrights}

Copyright for this article is retained by the author(s), with first publication rights granted to the journal.

This is an open-access article distributed under the terms and conditions of the Creative Commons Attribution license (http://creativecommons.org/licenses/by/4.0/). 